\title{
Mujeres en situación de prostitución de calle y su representación en medios gráficos: La historieta "Clara de noche""
}

\author{
al \\ Mariela Acevedo** \\ Recibido: 2 de abril de 2009 \\ Aprobado: 28 de abril de 2009
}

\begin{abstract}
RESUMEN
Este artículo presenta resultados de la investigación Construcciones discursivas de lo femenino y lo masculino en las historietas, realizada por la autora como un requisito para su grado. La idea de este trabajo es analizar las representaciones de las mujeres que ponen en juego los medios masivos de comunicación, construidas desde la visión del sujeto dominante en una sociedad patriarcal, teniendo en consideración conceptos centrales de la teoría feminista.
\end{abstract}

Entre estos discursos se destaca, la historieta Clara de noche (Suplemento NO de Página 12) ya que pone de manifiesto algunos argumentos tradicionales que esgrimen los clientes-prostituyentes cuando justifican su práctica, algunos de los cuales se asientan en el "sentido común" o más precisamente en imaginarios arraigados que naturalizan cierta visión de mundo. Se analiza la captura y puesta en discurso de sujetos mujeres doblemente subalternizados (clase y género) por medios de comunicación masiva, para observar cómo son presentadas las relaciones inter e intragénero y qué tipo de identidades y relaciones construye y naturalizan estos discursos.

Palabras clave: Prostitución, Mujeres, Patriarcado, Discursos, Medios de Comunicación.

* Este artículo fue presentado en las XII Jornadas Nacionales de Investigadores en Comunicación. Nuevos escenarios y lenguajes convergentes.Rosario-Santa Fe-Argentina 2008

** Estudiante de la Licenciatura en Comunicación y el Profesorado de Ciencias de la Comunicación- Facultad de Ciencias Sociales de la Universidad de Buenos Aires. Dirección electrónica: marunga00@hotmail.com 


\title{
Prostitutes on streets and their representation in graphic media: The story "Clara de Noche."
}

\begin{abstract}
This article shows the results of a research called: "Construcciones discursivas de lo femenino y lo masculino en las historietas", conducted by the author as a requirement to be awarded her degree.

The principal idea of this article is to analyze the representation of women showed in mass media using principal concepts of the feminist theory. These representations are usually constructed by men in a male centered society.

The comic "Clara de Noche" (supplement No. by Página 12) shows some of the traditional arguments used by brothel's clients when they justified their acts. Some of them are sustained in "common sense" or in very strong ideas that defend a certain vision of the world.

This article analyzes the catch and putting in speech by subject women doubly subordinate (class and gender) by mass media. We will examine how this vision presents inter an intra gender relationships, and what kind of identities and relationships make up and naturalized a male centered discourse.
\end{abstract}

Key words: Prostitution, women, patriarchy, speeches, mass media. 


\section{PROSTITUCIÓN Y SU REPRESENTACIÓN EN LOS MEDIOS}

La prostitución ha sido un tema visitado y revisitado en los discursos periodísticos, cinematográficos, literarios y académicos desde diversos ángulos: en general, se enfocan en las mujeres, a quienes consideran como víctimas o como poseedoras de una sexualidad desbordante; como explotadas o como sumamente inteligentes por obtener beneficios a cambio de un momento de placer, han sido construidas como las "otras", mientras que el polo positivo son las mujeres "decentes", madres y esposas. La mayoría de estas construcciones discursivas presentan un cierto orden de las cosas como naturales e inmutables; otras ofrecen una mirada crítica, pero, en general, tienden a invisibilizar el otro actor de la relación: el varón que ejerce el rol de padre/ esposo en el espacio privado del matrimonio y el de "cliente" o prostituyente en el espacio público de la prostitución.

La idea de este trabajo es analizar las representaciones de las mujeres puestas en juego en la historieta Clara de noche, construidas desde la visión del sujeto dominante en una sociedad patriarcal. Y esto se debe a dos motivos: en primer lugar, esta historieta expone, de manera evidente, algunos argumentos tradicionales que esgrimen los prostituyentes cuando justifican su práctica, algunos de los cuales se asientan en el "sentido común" o más precisamente en imaginarios arraigados que naturalizan cierta visión de mundo. En segundo lugar, este trabajo desea ser la primera aproximación de una más amplia que explore aspectos presentes en esta historieta como las relaciones intergénericas entre varones y los ritos de reafirmación de la masculinidad en la prostitución.

Más allá de que en una primera lectura la historieta presenta los argumentos tradicionales con los que se naturaliza la prostitución como trabajo (como el oficio más viejo del mundo o como una forma de hacer plata fácil), un acercamiento más detenido de las relaciones y de la representación de los arquetipos que pone en escena la tira permite ver que tras las concepciones sexistas y las formas de legitimación de la opresión genérica, también emergen elementos que contradicen y ponen en evidencia la violencia que ejercen los varones prostituyentes sobre las mujeres prostituidas.

\section{CLARA DE NOCHE, LA HISTORIETA}

Sinopsis: Desde 1992 se publica en el suplemento NO del diario Página 12 y en el diario Jueves, de España la tira semanal Clara de noche, con guión de los argentinos Carlos Trillo y Eduardo Maicas y dibujos del español Jordi Bernet. La historieta narra la vida de Clara Fernández, madre soltera y sola, quien se prostituye en la calle y se reivindica como trabajadora sexual. Clara es representada como una joven y sensual mujer, que considera que la prostitución es un trabajo que no la hace feliz, pero por momentos disfruta. A pesar de las culpas que esto le produce, como tiene un niño que mantener y cuentas que pagar, no tiene más remedio que hacerlo. Justamente, es el personaje de Pablito, el hijo de Clara, el que aporta el elemento de mayor conflicto a la trama, ya que la imagen de "la puta feliz" entra en contradicción ante los cuestionamientos del niño.

Estructura narrativa: la puesta del discurso como historieta da cuenta de que estamos ante una narrativa compuesta por dos lenguajes, uno icónico y otro verbal, inserta en un medio discursivo de lógica masiva y determinada fuertemente por éste en su función de entretener (Berone, 2006). La secuencia narrativa está compuesta, en general, por doce viñetas, en las que se narra una historia que comienza y concluye en la misma emisión. 
Podemos decir que apela a recursos que ponen de manifiesto la función poética del lenguaje, ' como la hipérbole, la ironía y la metáfora, para producir un efecto humorístico. Este efecto de sentido es resultado de una proyección, de cierta identificación, pero también de un distanciamiento. Algo nos divierte porque conectamos esa realidad "ficcionada", representada, con hechos cotidianos que reconocemos en nuestra vida diaria y que coinciden con nuestra visión del mundo. La historieta que presentamos suele resultar cómica sólo a varones; muchas mujeres la detestan porque les produce el efecto contrario. ${ }^{2}$ Por otra parte, también podemos decir que a través del humor, se refuerza el sentido asimétrico de las relaciones "porque se infiltra acríticamente y nos ciega respecto de la carga valorativa de su contenido" (Campagnoli, 1997).

Con respecto al mecanismo que pone en circulación este discurso, podemos decir, brevemente, que la captura de sujetos doblemente subyugados (de clase y de género) por un medio de comunicación masiva, por su propia lógica masificante, despolitiza y elimina el conflicto. Así las relaciones de dominio y sumisión entre varones y mujeres son presentadas como transacciones mercantiles o como infidelidades entre esposos. ${ }^{3}$

Podemos distinguir un primer nivel de lectura, en el que se desarrolla la trama, con sus protagonistas, temas y motivos que estructuran la acción. Y un

1 La función poética es aquella que alcanza a los valores constructivos del mensaje destinados a producir un sentimiento o efecto en el destinatario, mediante las modulaciones expresivas. Ver (Roman Jakobson 1986).

2 Me remito a críticas feministas que consideran que "El contenido [de la historieta "Clara de Noche"| es escandalosamente agresivo, denigrante y violento hacia las mujeres" en http://ningunamujermas.wordpress.com/2007/1 1/08/clarade-noche-violencia-de-genero-y-deshumanizacion-dela-mujer/

3 Para los procesos de captura de lo popular en lo masivo y la lógica de los procesos de masificación, ver Martín Barbero (1987). segundo nivel de lectura, en el que podemos dar cuenta de cómo se construyen, afirman y perpetúan ciertas visiones de mundo que "a través de configuraciones discursivas (...) construyen un cierto orden de las cosas y los sucesos que lo habitan" (TRAVERSA, 2001). Este segundo nivel es el que nos interesa para dar cuenta de las maneras en las que los personajes femeninos son representados como estereotipos de los arquetipos de madre/esposa y puta.

Las preguntas que podemos hacernos en este nivel son:

- ¿Cómo son representadas las mujeres?

- ¿Qué atributos físicos destacan en unas y otras?

- ¿Cuáles son los lugares donde son principalmente representadas?

- ¿Qué tipo de acciones realizan?

- ¿Qué tipos de relaciones establecen entre ellas?

- ¿Cuáles son las representaciones obturadas en este discurso?

Muestra del corpus. Para la realización de este trabajo se analizaron las historietas publicadas por el suplemento No de Página 12 entre enero 2002 y julio 2008, a las cuales se accede en el sitio web del diario. Un primer ordenamiento se hizo entonces por fecha, luego se determinaron categorías (no excluyentes): 1. ME/P (representaciones de madres-esposas y su relación con las putas), 2. M (representaciones de maternidad en la prostitución), 3.T (representaciones de prostitución=trabajo), 4. H/N (representaciones que ubican la prostitución en la historia o que la naturalizan) 5. P (representaciones de prostituyentes; en esta categoría se distinguen, en particular, las que ponían en evidencia representaciones de violencia física, violencia verbal, violación o tortura) y 6. F (representaciones de fiolos (en 
lunfardo: rufián que sólo explota a una mujer), encubiertos en personajes "amigos" o familiares de la protagonista).

Finalmente, se buscaron patrones de repetición en las representaciones y se seleccionaron ejemplos de estas características en aquellas que se consideran más representativas del corpus de la categoría 1. ME/P, 2.M, 3.T y 4 $\mathrm{H} / \mathrm{N}$ (las categorías 5.P y 6.F referidas a las figuras masculinas exceden los propósitos de este trabajo) tomando algunos cuadros o viñetas que ilustran los conceptos que queremos destacar en el discurso.

\section{LA EXPLOTACIÓN SEXUAL DE MUJERES EN EL SISTEMA PATRIARCAL}

Siguiendo a Kathleen Barry, tanto la prostitución como el matrimonio son instituciones fundamentadas en la explotación sexual de las mujeres. Barry considera que la explotación sexual se da en diferentes formas y grados, y la forma extrema de explotación se presenta en las situaciones "en las que una mujer o niña no pueden cambiar las condiciones inmediatas de su existencia al margen de cómo puedan haber llegado a esa situación de la cual no pueden salir y del lugar en el que sean sometidas a la violencia y explotación sexuales" (Barry, 1987, p. 179). En esta definición de explotación sexual queda incluida la prostitución, que desde esta perspectiva no se visualiza como elección.

Marcela Lagarde también considera la prostitución como una forma de sujeción de algunas mujeres a todos los varones y afirma que "en la prostitución se reproduce el patriarcado en su conjunto, se recicla el sistema para que todo quede otra vez en su lugar" (Legarde, 1997, p. 578).

Ambas consideran que la prostitución no es una relación entre privados, sino que se trata de relaciones de dominación en un sistema que somete a las mujeres y las priva del derecho sobre su cuerpo, y ambas consideran que los lazos que mantienen la prostitución y el matrimonio son más estrechos que lo que se cree. En ese sentido Lagarde expresa que

Las ideologías han hecho ver a las madresposas y a las prostitutas como antagónicas e incluso incomparables, pertenecientes a ámbitos (naturalezas) distintas. En este sentido las ideologías son distorsionadoras de la realidad mediante la extrapolación de las diferencias y la anulación de las similitudes, incluso al definir con nombres distintos hechos semejantes (Lagarde, 1997, p. 565).

Marcela Lagarde desarrolla el concepto de cautiverios para dar cuenta de cómo en las sociedades patriarcales las mujeres están destinadas a la sujeción a los varones en distintas instituciones: postula la categoría de madresposa para la mujer que a través de un pacto entre varones -entre padre y futuro marido- es destinada para su uso privado en el matrimonio; y utiliza puta para las mujeres que por el pacto entre varones -entre proxeneta y prostituyente- son destinadas al uso colectivo en la prostitución a la que considera un cautiverio público.

En las representaciones sociales estas instituciones son construidas y valoradas de manera antagónica y encarnadas por las mujeresobjeto que secuestran: la madresposa, valorada como mujer decente, y la puta, estigmatizada como mujer perdida. A su vez, existe un discurso pseudo-progre que otorga a la mujer en prostitución el estatus de mujer sexualmente liberada, que pasa por alto que la puta no obtiene placer en la relación sexual prostibularia, no elige a su compañero sexual ni muchas de las condiciones de la explotación de su cuerpo. 


\section{PROSTITUCIÓN: \\ LA ESCLAVITUD MÁS VIEJA DEL MUNDO}

Entender que la prostitución no es un trabajo sino una forma de explotación sexual implica comprender primero la simbolización de las diferencias sexuales, que en las sociedades patriarcales, además de ser traducidas a un código binario excluyente, (masculino/femenino), son jerárquicas (una de las representaciones tiene mayor valor que la otra) y androcéntricas (es decir, que los valores dominantes que moldean discursos y prácticas son los masculinos)

Es importante destacar que, siguiendo a Marta Lamas, entendemos la construcción del género como una operación de simbolización de las diferencias sexuales, que en nuestra sociedad traduce las diferencias en desigualdad. La subordinación femenina no es así algo "natural", como tampoco lo son la heterosexualidad y prácticas como la prostitución (Lamas, 1993).

Antes de analizar la construcción discursiva específica de los estereotipos femeninos, podemos dar cuenta de los supuestos que sostienen el discurso de la prostitución como trabajo: estos son, en particular, tres: la prostitución como un pacto entre iguales, la idea de "lo eterno" de la prostitución y la encarnación de la prostitución en la figura de "la puta" como esencia de la mujer (Verslic, 2007).

\section{EL PACTO ENTRE IGUALES: SÍ, ENTRE PROXENETA Y PROSTITUYENTE}

El sentido común da cuenta de esta relación libremente consensuada entre mujer y cliente.

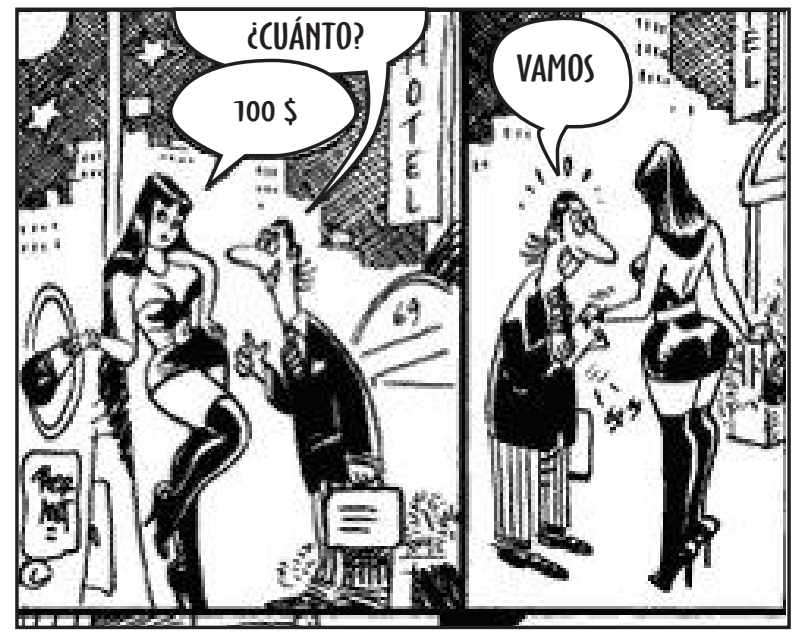

"El pacto entre iguales"

Según María Galindo, el pacto que se da en la prostitución

No es una relación directa prostituyente-prostituta, sino que es un contrato prostituyente-proxeneta, igual que todos los contratos sexuales en la sociedad patriarcal son contratos entre hombres sobre el intercambio de los cuerpos, la fuerza de trabajo y la vida de las mujeres (...) Ella es un objeto porque el contrato no es con ella sino sobre ella y su cuerpo, que es bien distinto (Galindo, 2007, p. 138).

Esta es una gran omisión en la historieta: a pesar de que Clara es una mujer que se prostituye en la calle, ella no tiene proxeneta. Según Sonia Sánchez, son muy pocas las mujeres que pueden estar en la calle sin un fiolo o "marido"; estas mujeres -consideradas "locas sueltas"- son perseguidas por la policía, los proxenetas y las mismas mujeres en situación de prostitución. Sánchez asegura, además, que quienes se prostituyen en la calle deben pagar coimas policiales y recibir protección de figuras masculinas que aseguren que el "cliente" cumpla con el dinero o el tiempo pactado. Nada de esto es visibilizado en la historieta. 


\section{ETERNO RETORNO}

Con el tópico del "oficio más viejo del mundo", se pretende como universal e inmutable una forma de explotación sobre el cuerpo de las mujeres. Lo que oculta el sentido común es que las mujeres históricamente han estado sujetas a un varón y en el caso de las mujeres prostituidas a un proxeneta, que es quien se beneficia de la explotación del cuerpo de las mujeres que regentea.
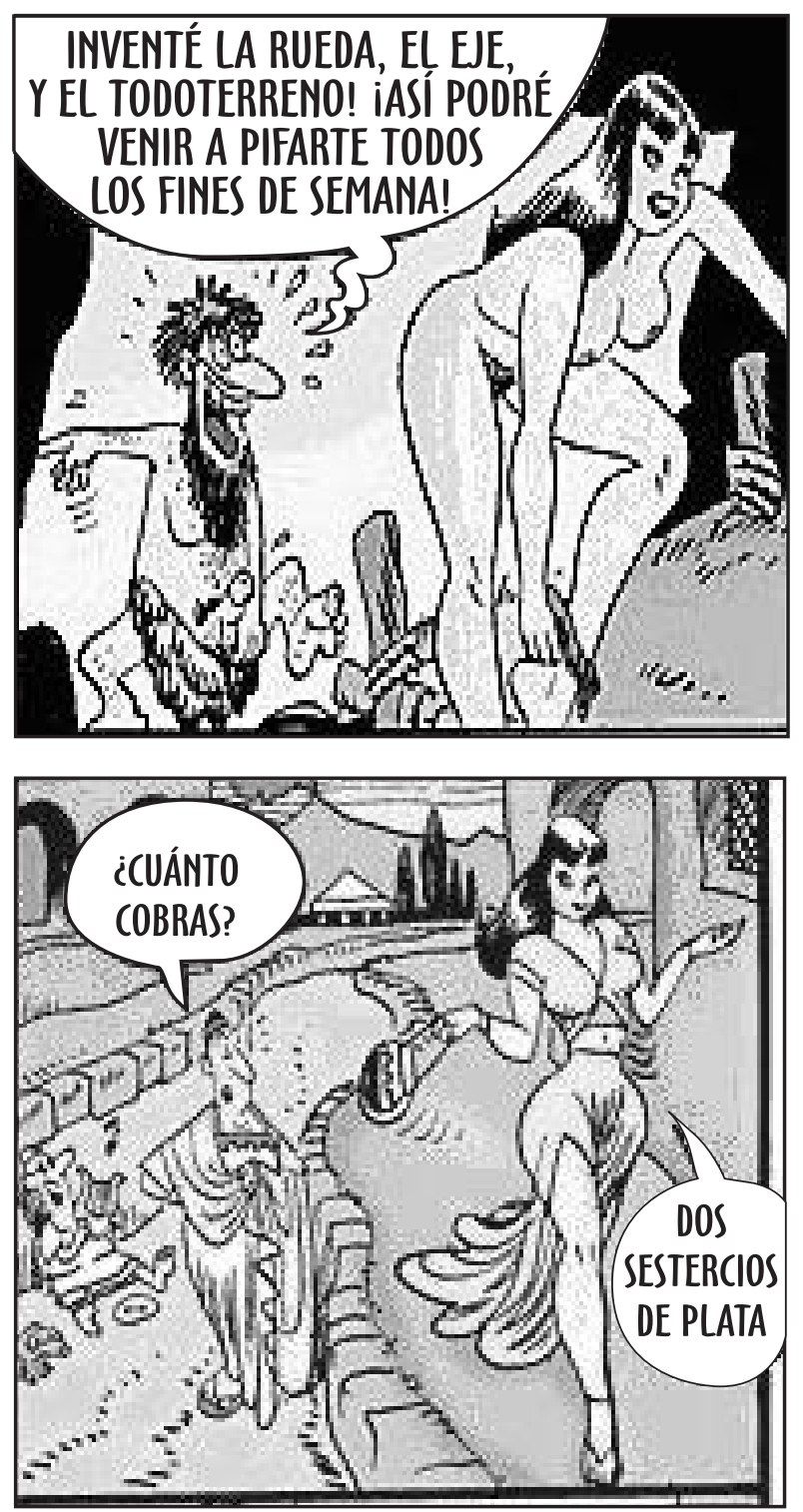

"El eterno retorno"
El oficio más viejo del mundo, como dice Barry, es el de proxeneta, porque detrás de toda mujer prostituida hay un explotador. En Clara de Noche la forma de universalizar este tópico es presentando una genealogía mítica de la protagonista, que sitúa a sus antepasadas en diferentes países y épocas ejerciendo la prostitución, o incluso mostrando que las putas fueron parte de la creación de un dios (masculino claro)

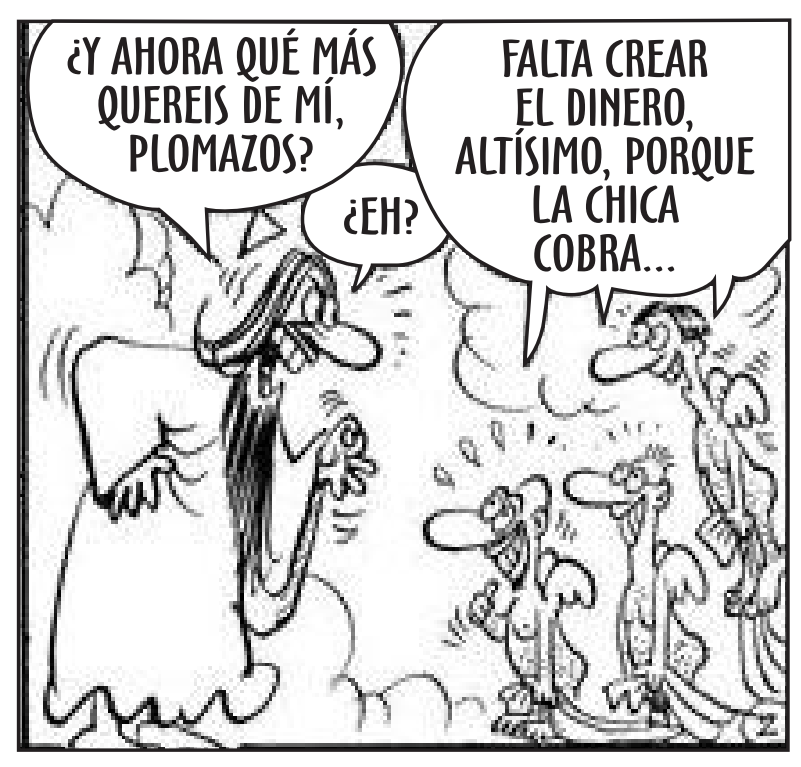

"Son putas (y les gusta)"

Otro de los tópicos constantemente repetidos por prostituyentes es el de la puta como un colectivo de mujeres "especiales". Ellas están ahí, paradas en la esquina, porque son distintas a otras mujeres. Lo que oculta este razonamiento es que en la especialización que destina mujeres a diferentes cautiverios, a algunas les ha tocado convertirse en el cuerpo de todas para ser humilladas y degradadas por todos. En esta argumentación también se cruza la idea del "consentimiento": ellas eligen ser putas. Es más, las mujeres que eligen ser putas, representadas por Clara, no sólo tienen una estirpe de putas, por lo que han 


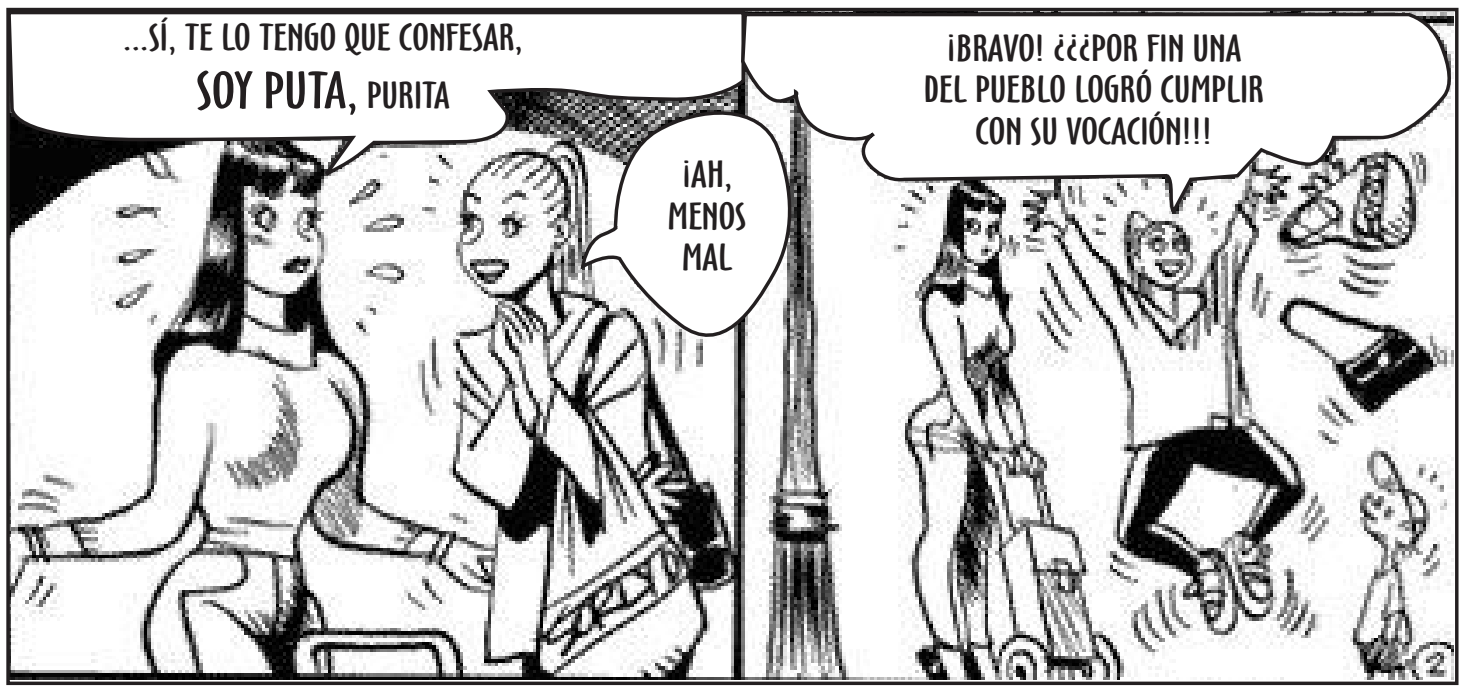

"Especialización de las mujeres: Las buenas y las otras".

heredado la "profesión" vía las mujeres de la familia, sino que, además, tienen una vocación de putas que se empeñan en cumplir.

En este sentido, es pertinente citar a Bourdieu:

No se puede pensar de modo adecuado esta forma particular de dominio más que a condición de superar la alternativa ingenua de la contención y el consentimiento, de la coerción y la adhesión: la violencia simbólica impone una coerción

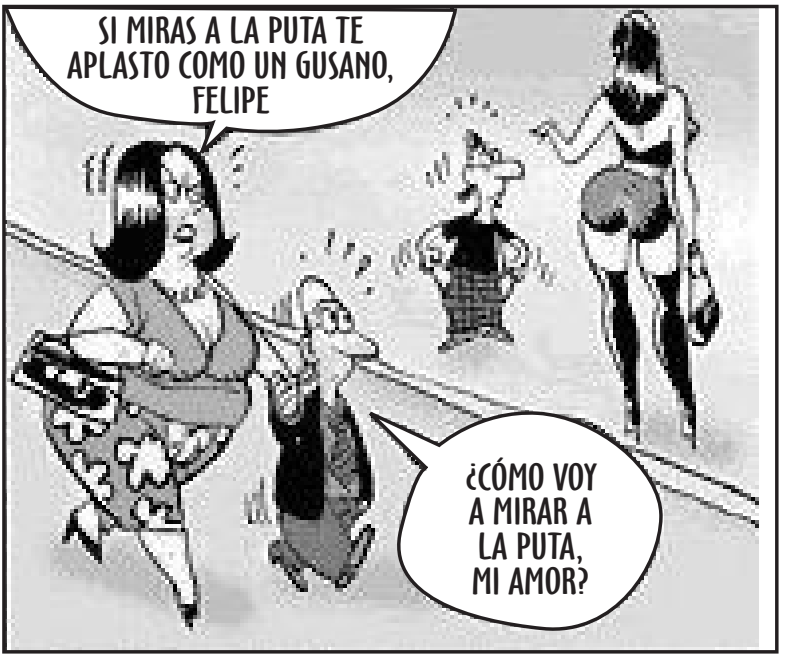
que se instituye por medio del reconocimiento extorsionado que el dominado no puede dejar de prestar al dominante al no disponer, para pensarlo y pensarse, más que de instrumentos de conocimiento que tiene en común con él y que no son otra cosa que la forma incorporada de la relación de dominio (Bourdieu, 2009).

Especialización de las mujeres: Las buenas $y$ las otras. Las madresposas: Las madresposas en Clara de Noche están valoradas negativamente, son en su mayoría gordas, feas y agresivas.

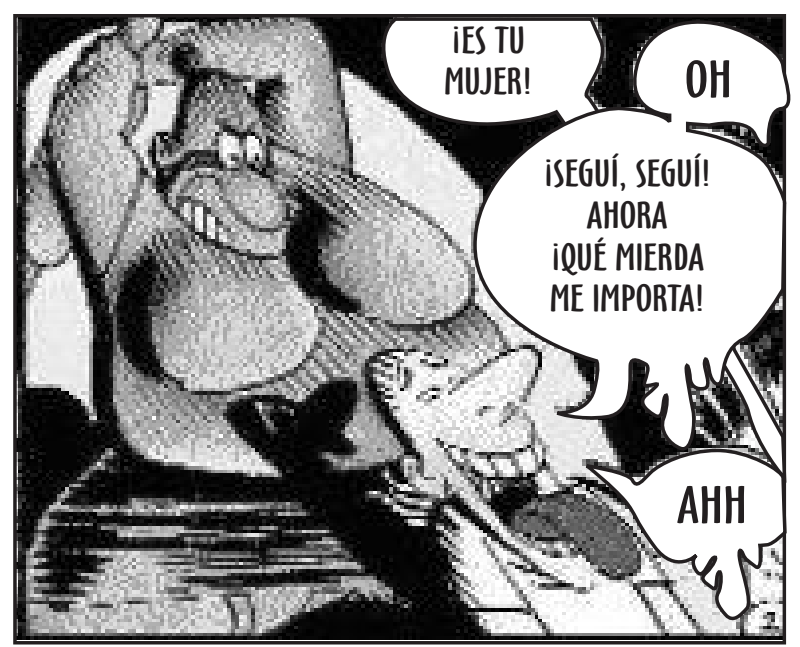



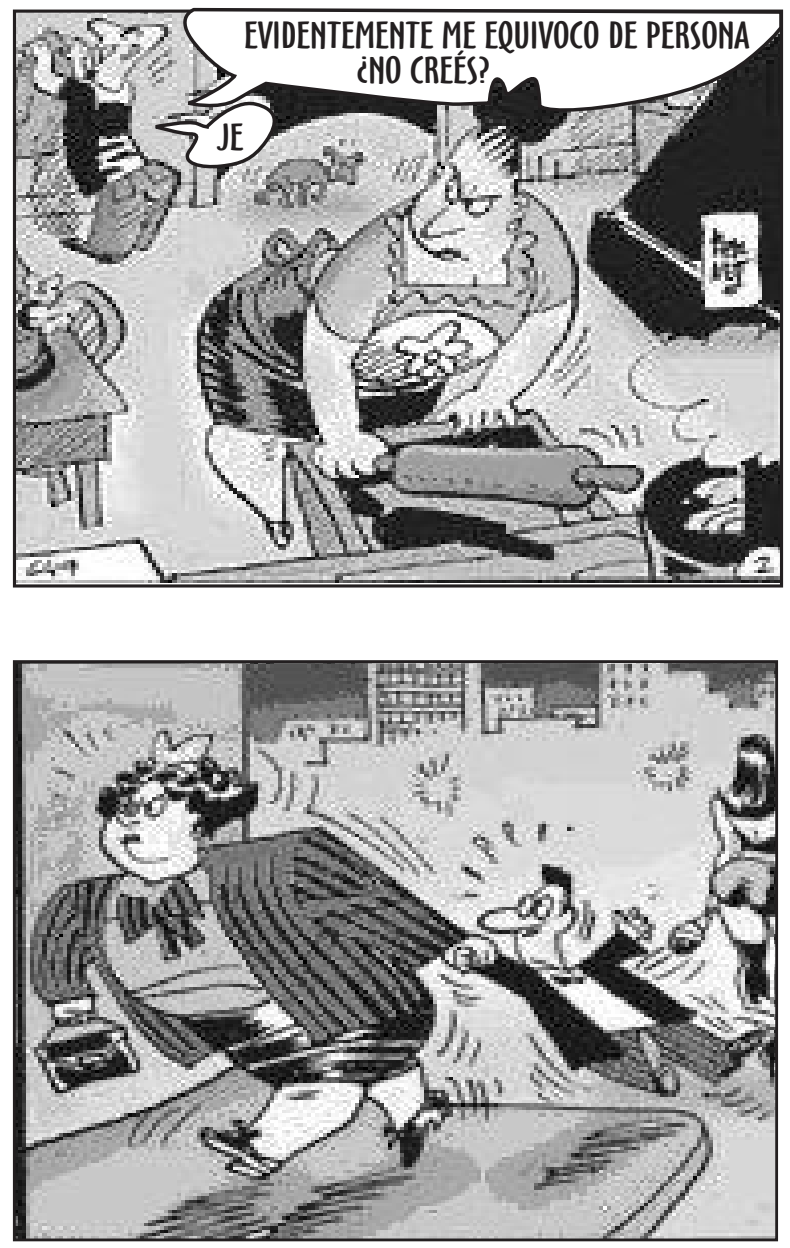

Las madresposas

En general, son representadas en el espacio privado del hogar, ya que todas son amas de casa.

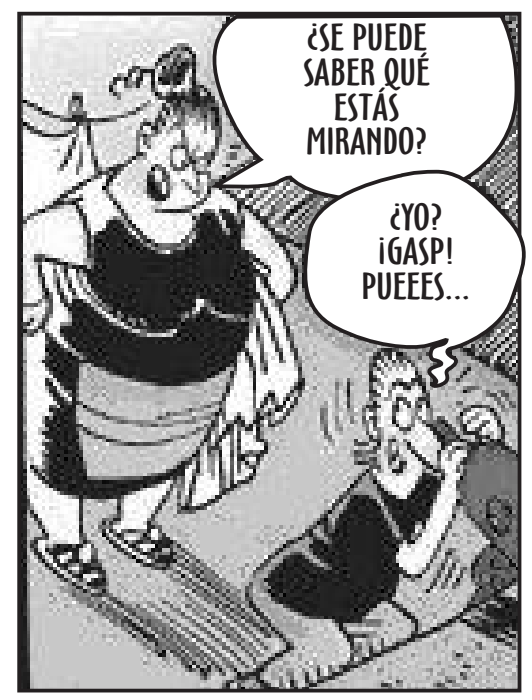

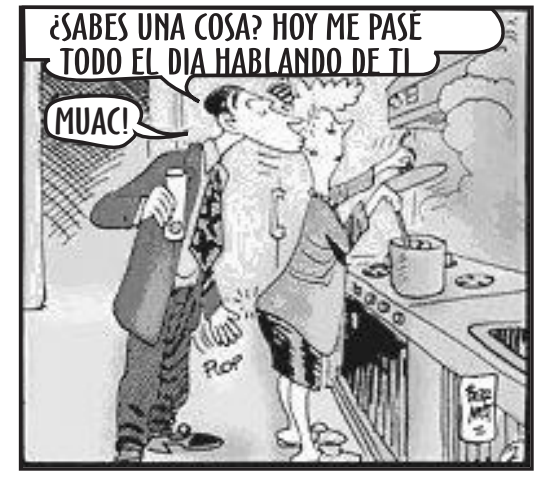

Sobre el espacio doméstico/público

Cuando aparecen en el espacio público lo hacen "incursionando": de compras o de paseo en compañía del marido.
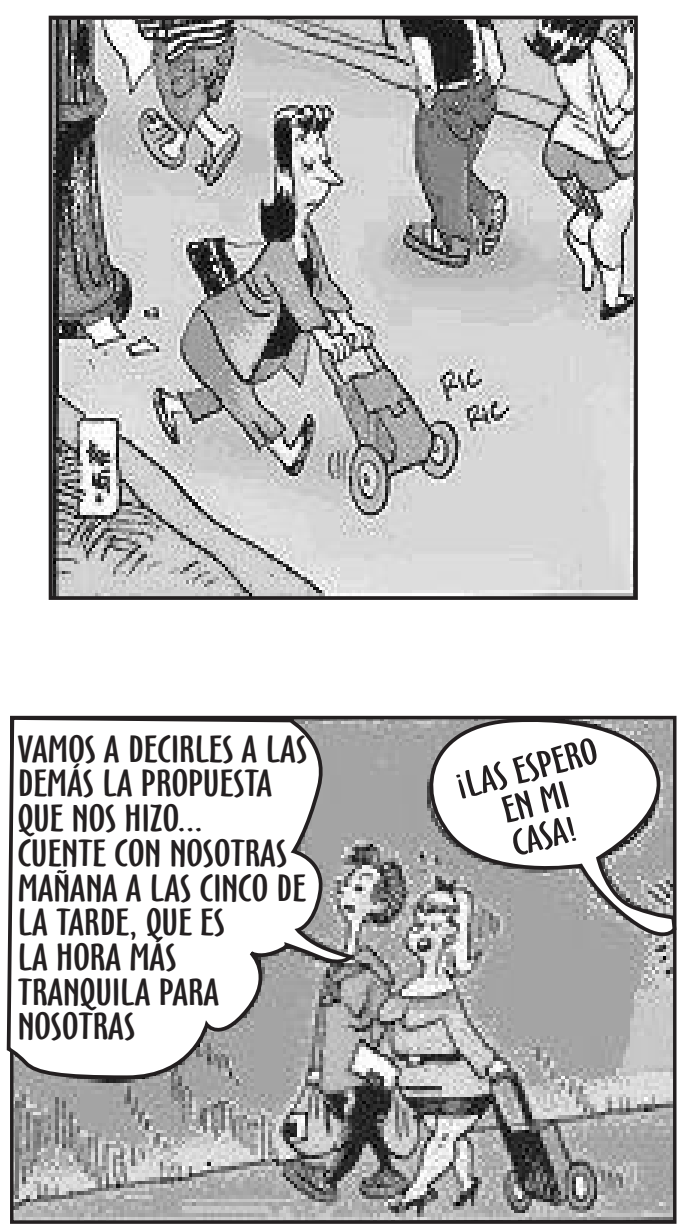

Sobre las relaciones sexuales

Con las madresposas las relaciones sexuales son siempre insatisfactorias, los 
maridos apelan a las putas (o a su fantasía) para conseguir lo que no tienen en su casa.
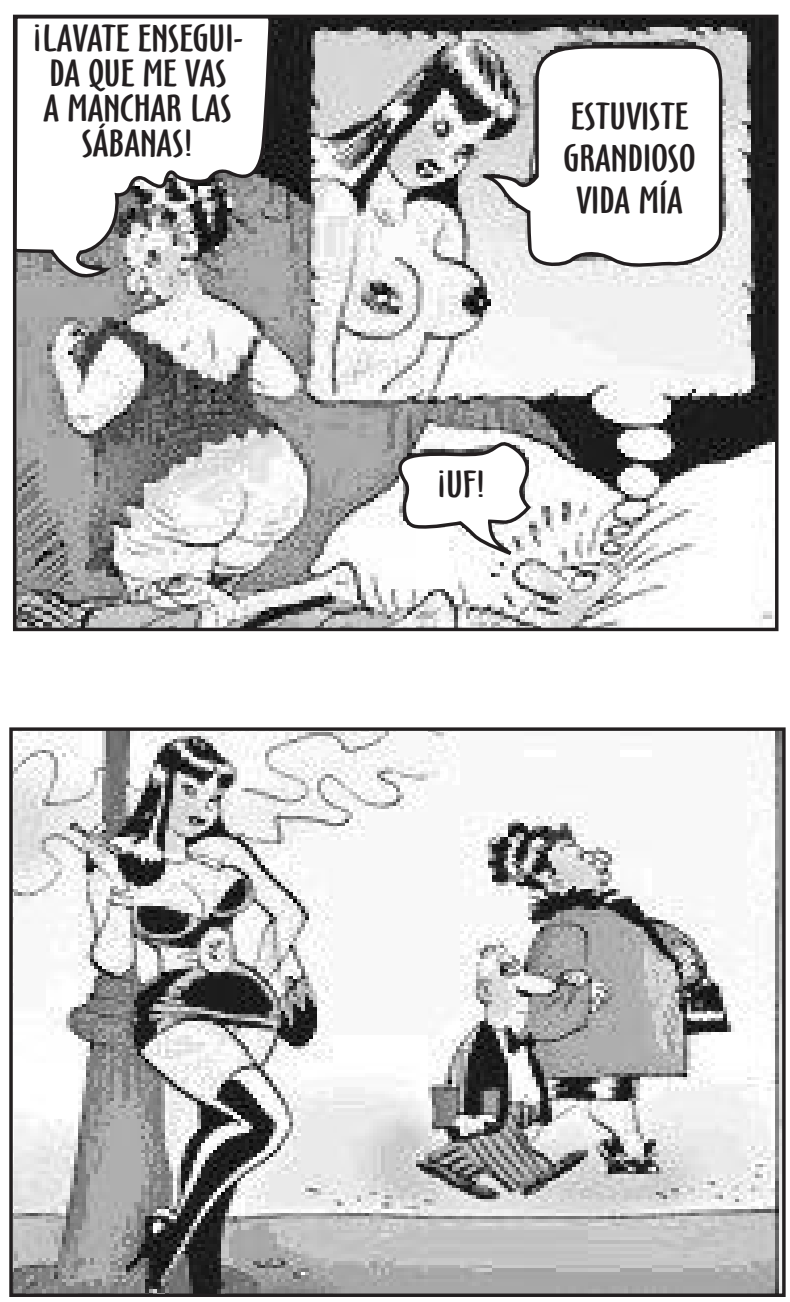

Las putas

Las putas. En Clara de Noche las putas están valoradas positivamente como mujeres que realizan un servicio de demanda masculina: son comprensivas, sexis e insaciables, pero también son anorgásmicas, la relación sexual prostitucional no produce ningún tipo de placer a las mujeres en situación de prostitución que fingen el orgasmo para el prostituyente.

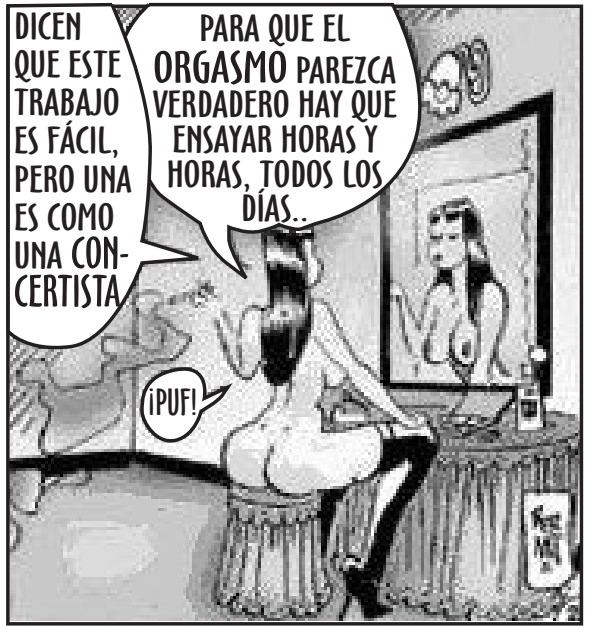

Sobre la falta de orgasmo

Las putas son las únicas mujeres que transitan el espacio público como "trabajadoras". Los episodios de violencia que sufren las putas, se resuelven con el pago de dinero, así, violaciones, golpes y torturas, pasan como "gajes del oficio" que las mujeres deben enfrentar por su elección laboral.

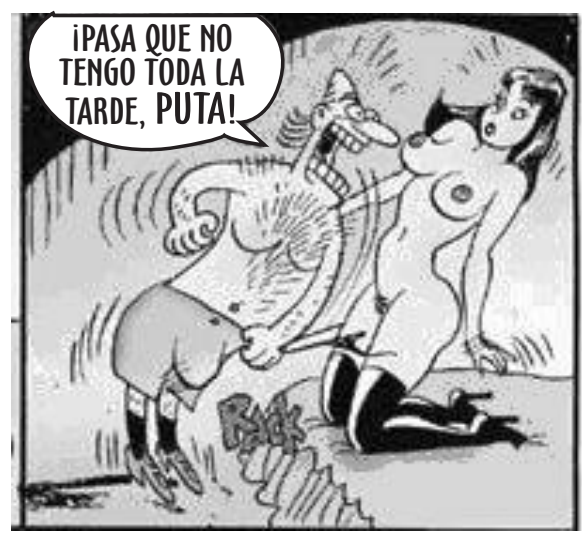

Sobre la violencia

Las esposas sexis. En Clara de Noche hay un tipo de madresposas que se ven atractivas. Son aquellas mujeres que desean complacer al marido y apelan a las putas para aprender cómo hacerlo. De ellas aprenden no sólo cómo darles placer a los varones sino también cómo fingir orgasmos. 


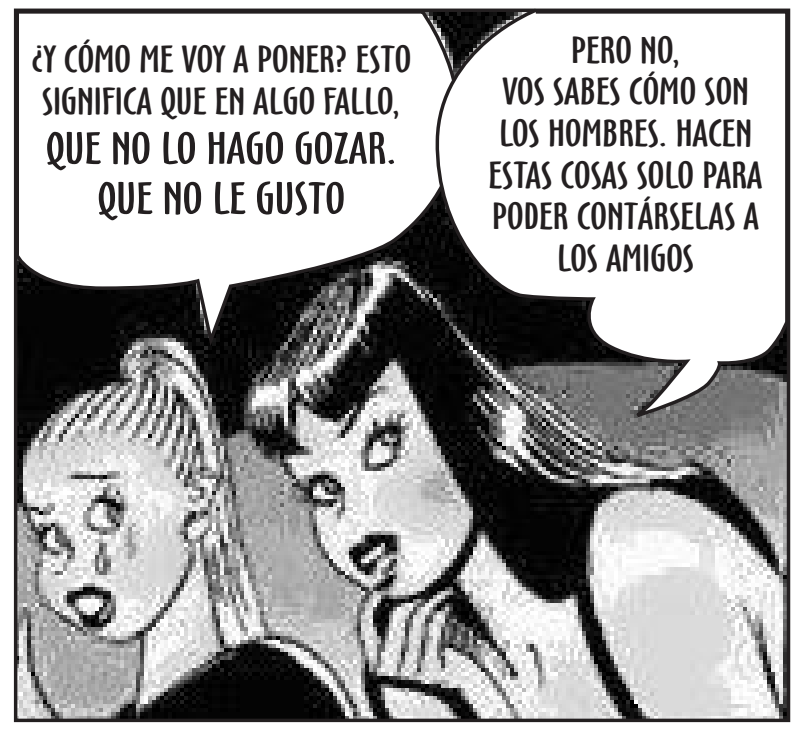

"Las esposas sexis"

Se reafirma así una forma de sexualidad subordinada, en la que el placer de la mujer pasa por la satisfacción de la demanda de los varones. Esta es la única forma de alianza que existe entre madresposas y putas, una alianza que tiene como punto de partida no el cuestionamiento de la opresión de unas y otras, sino los deseos de los varones.

\section{LA MUJER ANDROCÉNTRICA}

El único caso relevado en el corpus de representación de mujer trabajadora e independiente, se trata de una atractiva mujer prostituyente.

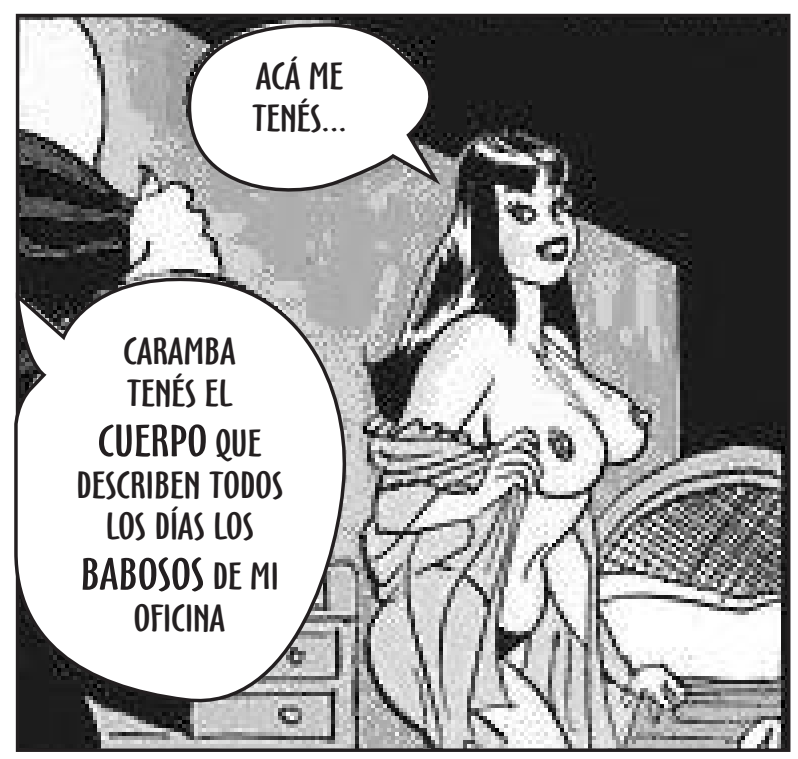

Es decir, que se puede apreciar la construcción androcéntrica de la escena lésbica pensada en función del deseo masculino en la que la mujer adopta incluso los valores y prácticas de los sujetos dominantes.

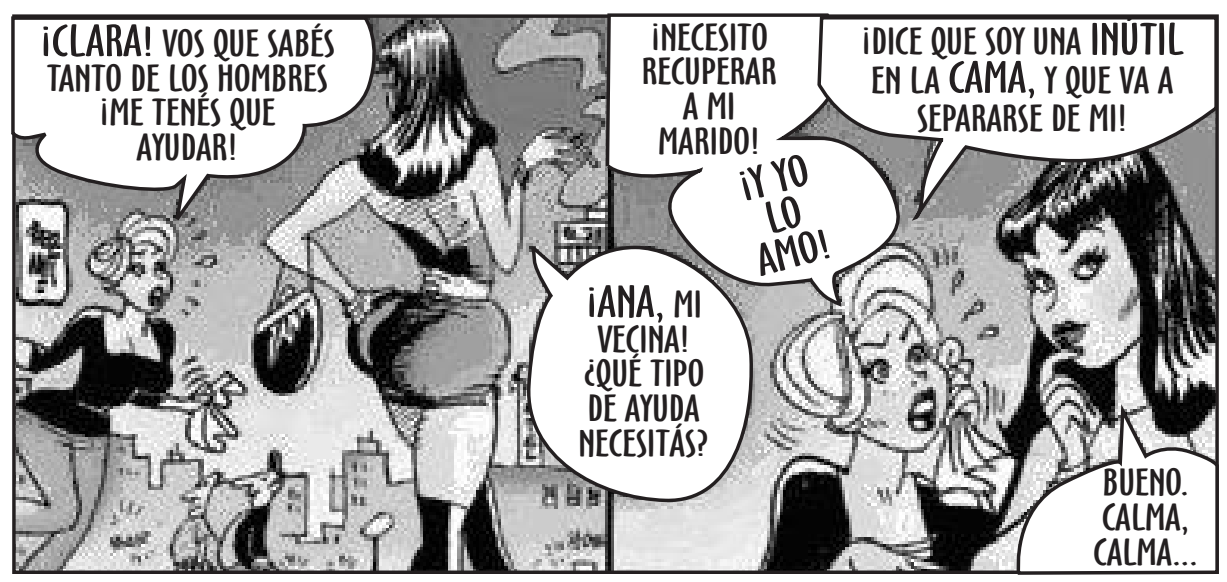

La mujer androcéntrica 


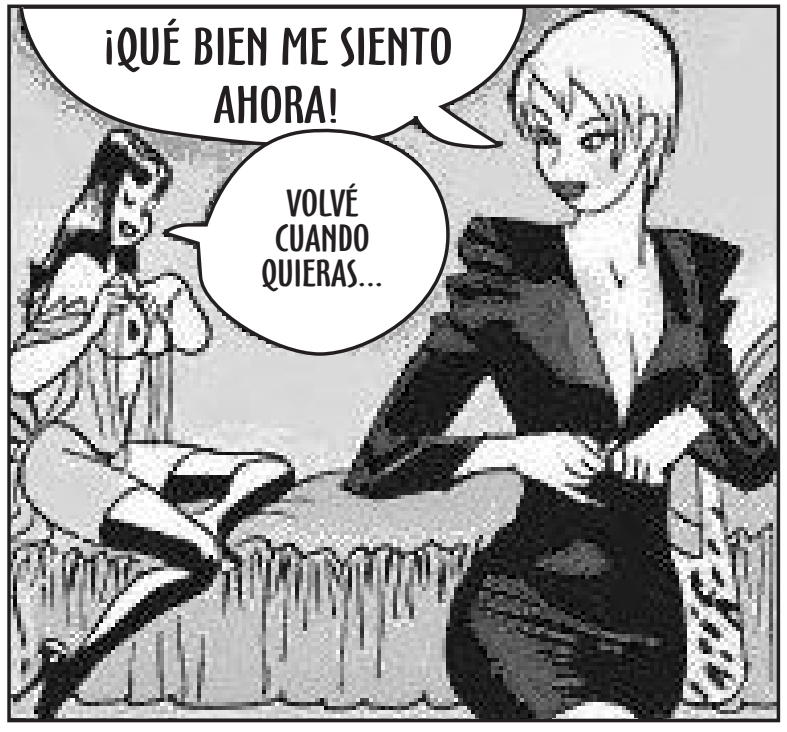

(El pago por acceso al cuerpo de las mujeres es una práctica netamente masculina)

Cuando la puta es madre: las representaciones de "la puta feliz" suelen esconder otros aspectos de la vida de las mujeres, entre los que se encuentra el de ser madre. La historieta analizada tiene el mérito de abrir esa representación obturada en otros discursos y poner de manifiesto contradicciones y ambigüedades que permiten arriesgar que hay más que sexismo y representaciones de lugares comunes en la tira. Las contradicciones que enfrenta la protagonista, sin embargo, parecerían reducirse al hecho de encarnar dos modelos en conflicto: el de la buena madre o el de la mujer perdida, y se puede intuir que el mensaje desliza que si no fuera madre, la situación de la protagonista dependería de su libre elección y no de estructuras económicas y culturales arraigadas social e históricamente. Resulta, así, complicado definir el alcance de la representación de maternidades que no se ajustan a la norma tradicional, aunque puede considerarse que este conflicto es uno de los más complejos de la trama.

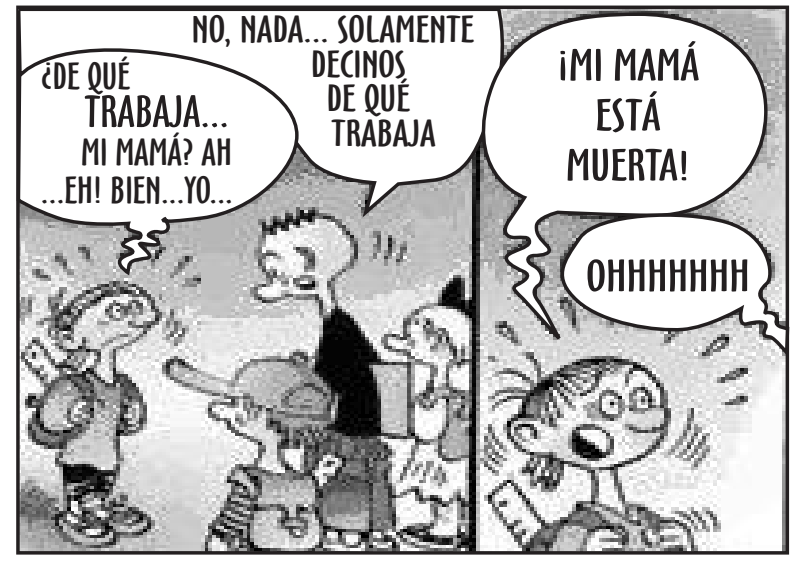

"Cuando la puta es madre"

En la figura de Pablito, además, se cruzan deseos y expectativas contradictorios: por un lado siente vergüenza de su madre y desea que deje de prostituirse; por otro lado, opera como el responsable de su explotación, no sólo porque Clara afirma en más de una oportunidad que se prostituye para poder darle todo a su hijo, sino también porque éste emplea mecanismos de extorsión o realiza exigencias que sabe que deben ser cumplidas con el dinero que obtiene la madre en la prostitución. De esta forma se puede decir que Pablito opera, en algunas ocasiones, como proxeneta de su madre.

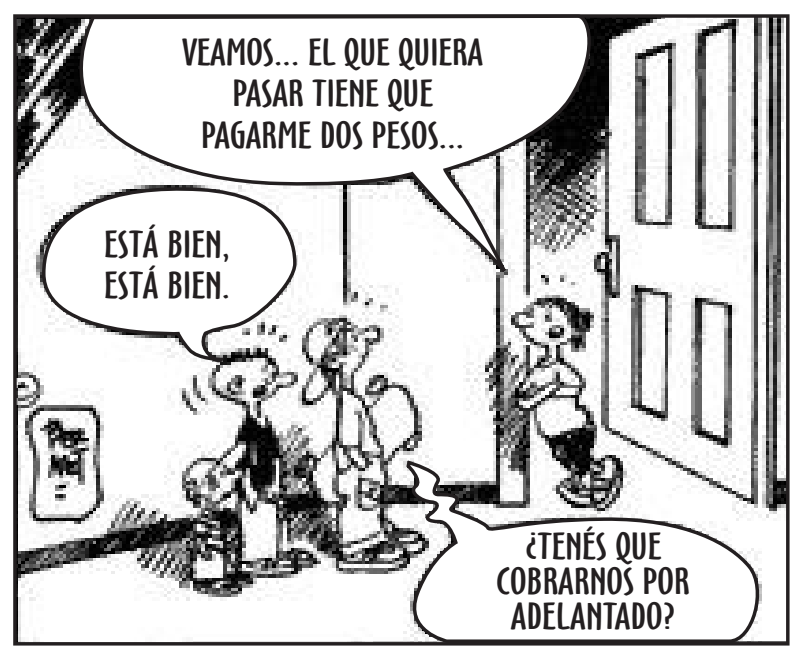




\section{CONCLUSIONES}

La representación de las mujeres en Clara de Noche presenta como antagonistas a las madresposas y a las putas. La valoración que se hace de unas y otras es contraria a la que usualmente se percibe en discursos y prácticas sociales: en la tira aparecen estigmatizadas las madresposas, mientras que las putas son valoradas y reconocidas. La tira plantea la oposición como moralismo versus progresismo: las madresposas son las que juzgan duramente a las putas, discurso que comparten con la iglesia, mientras que las putas son presentadas como sexualmente liberadas de esos y otros prejuicios.

Las mujeres "tradicionales", reservadas al espacio privado del hogar, son las dominantes en la relación de esposa-esposo y los esposos revierten o se "vengan" de esta dominación en el uso de mujeres "públicas". Al definir la prostitución como "trabajo" se produce un sistema consolatorio para el prostituyente: ir de putas es ayudar a éstas a mantener su vida y la de los suyos, y no una práctica opresiva.

Para sostener el discurso de que la prostitución es trabajo, se le cede el mecanismo de enunciación a representaciones de mujeres en situación de prostitución desde una óptica masculina. Se exponen, así, de manera evidente argumentos tradicionales que esgrimen los prostituyentes cuando justifican su práctica, como la idea del "contrato entre iguales", la antigüedad de esta forma de explotación y "la puta" como forma esencial de algunas mujeres. Se oculta la explotación que ejercen los varones, al eliminar figuras conflictivas como el proxeneta o el policía que cobra coima para dejarlas "trabajar". Sin embargo, la historieta también pone en evidencia aspectos generalmente poco visibles de las mujeres en situación de prostitución: cómo transitan ellas la maternidad, la inexistencia de placer para la mujer en la relación prostibularia y el grado de violencia al que están expuestas cuando enfrentan a un prostituyente.

Este trabajo puede considerarse como parte de un trabajo más amplio que contemple la construcción discursiva de lo femenino y lo masculino en relación con lo que Foucault denomina las condiciones de posibilidad de los discursos con base en la materialidad de las prácticas. En ese sentido, Cristina Molina sostiene que el hecho de que las representaciones de mujeres y varones sean una construcción discursiva "no debe hacernos perder de vista que el discurso se impone por el poder y que el mismo discurso es posible porque se puede hablar y hacer callar a otros" (Molina, 2003, p.140).

La apuesta teórica es política: ¿por qué cuestionar estos discursos desde una mirada feminista? Molina expresa que

La teoría feminista no es sólo un discurso descriptivo sobre la situación de las mujeres, y una reivindicación para que cambie. Es también un discurso crítico sobre ellos, sobre lo que han hecho ellos. Es importante que los hombres se sientan "discurseados" -como diría Celia Amorós-, que se sientan objetos de discurso, que se sientan mirados, nombrados y criticados: si la mirada del otro nos ha constituido en objetos, tenemos que mirarlos nosotras ahora, para ocupar la posición de sujetos (Molina, 2003, p. 144).

También Marta Lamas explica que "requerimos usar la perspectiva de género para describir cómo opera la simbolización de la diferencia sexual en las prácticas, discursos y representaciones culturales sexistas y homófobas". Partir de esta perspectiva nos permite deconstruir imágenes de lo femenino basadas en la naturalización de la mercantilización del cuerpo y la supuesta "naturaleza" de las mujeres a prostituirse para transformar el imaginario social que concibe la sexualidad femenina como pasividad pura y como 
deseo de ser-para-otro. Así, "comprender por qué ciertos significados tienen hegemonía nos lleva a investigar cómo pueden ser cambiados." (Lamas, p. 17)

Lamas nos recuerda que todo cuerpo está marcado por redes de poder que lo atraviesan: discursos de poder, que -siguiendo a Foucaultno sólo prohíben algunas formas de su expresión: también crean el cuerpo deseable y deseado para determinada cultura. "El cuerpo es un territorio sobre el que se construye una red de placeres e intercambios corporales a los que los discursos dotan de significados. Las prohibiciones y sanciones que le dan forma y direccionalidad a la sexualidad, que la regulan y reglamentan, pueden ser transformadas." (Foucault, p. 18) El desafío de transformar las relaciones entre los géneros implica comenzar por cuestionar sus representaciones.

\section{REFERENCIAS BIBLIOGRÁFICAS}

Barry, K. (1987). Esclavitud sexual de la mujer. Barcelona: LaSal Edicions de les dones.

Berone, L. (2006). La historieta como estructura híbrida de significación. Principios críticos". Ponencia presentada en las VII Jornadas Teatro-Cine-Narrativa: abordajes trandisciplinarios, Buenos Aires: octubre de 2006

Bourdieu, P. La dominación masculina. Extraído completo del sitio de la Universidad de Guadalajara http://www.udg. mx/laventana/libr3/bordieu.html\#cola. Recuperado el 2 de febrero de 2009.

Campagnoli, M. Lógica, metodología, sexismo en la Asociación de Psicólogos de Buenos Aires. Foro de psicoanálisis y género. III Jornadas de Actualización: Cuerpo y subjetividad: mujeres, varones, construcciones teóricas y experiencias de vida realizada el 18 de octubre 1997.

Galindo, M. y Sánchez, S. (2007). Ninguna mujer nace para puta. Buenos Aires: Lavaca Editora

Jakobson, R. (1986). Lingüística y poética. En: Ensayos de lingüística general. Barcelona, Planeta Agostini.

Lagarde, M. (1997). Los cautiverios de las mujeres: madresposas, monjas, putas, presas y locas. México: Universidad Nacional Autónoma de México.

Lamas, M. Usos, dificultades y posibilidades de la categoría 'género'. Ensayo elaborado a partir de la ponencia "Algunas dificultades en el uso de la categoría 'género'" presentada en la sesión Antropología de género: teoría y método" durante el XIII congreso de Ciencias Antropológicas y etnológicas. México: agosto 1993.

Martín Barbero, J. (1987). De los medios a las mediaciones. Comunicación, cultura y hegemonía. Barcelona: Gustavo Gilli.

Molina, C. (2003) Género y poder desde sus metáforas. Apuntes para una topografía del patriarcado. En: Tubert, S (comp.). Del sexo al género. Los equívocos de un concepto. Madrid: Ediciones Cátedra.

Traversa, O. y Moré, M. (2001) Acerca de la construcción del cuerpo en el período 1940-1970: un curso de semiotización de los medios de prensa. En: Cuadernos, febrero № 17 Universidad de Jujuy.

Vasallo, M. (2001). Vetusta fantasía para progres. Nota sobre Clara de Noche publicada en El Espejo en octubre 2001. 
Verslic, L. (2007) El Cliente es prostituyente. En: Brujas. Publicación Feminista. Año 26 No 33. ATEM-25 de Noviembre. Buenos Aires, octubre 2007.

\section{Historietas de Clara de Noche}

Los fragmentos que ilustran este trabajo fueron extraídos de www.pagina 12.com.ar de la sección NO suplemento semanal que se publica los jueves.

\section{Pacto entre iguales:}

http://www.pagina12.com.ar/diario/suplementos/no/clara-2002-02-21.html

\section{Eterno retorno:}

1. http://www.pagina12.com.ar/diario/suplementos/no/clara-2006-11-16.html

2. http://www.pagina 12.com.ar/diario/suplementos/no/clara-2005-07-07.html

3. http://www.pagina12.com.ar/diario/suplementos/no/clara-2002-07-11.html

\section{Son putas (y les gusta):}

1. http://www.pagina 12.com.ar/diario/suplementos/no/clara-2003-08-14.html

2. http://www.pagina 12.com.ar/diario/suplementos/no/clara-2002-06-20.html

\section{Las madresposas:}

1. http://www.pagina 12.com.ar/diario/suplementos/no/clara-2004-01-08.html

2. http://www.pagina12.com.ar/diario/suplementos/no/clara-2004-12-23.html

3. http://www.pagina 12.com.ar/diario/suplementos/no/clara-2005-01-13.html

4. http://www.pagina 12.com.ar/diario/suplementos/no/clara-2005-07-14.html

5. http://www.pagina 12.com.ar/diario/suplementos/no/clara-2005-1 1-03.html

6. http://www.pagina 12.com.ar/diario/suplementos/no/clara-2006-01-19.html

7. http://www.pagina 12.com.ar/diario/suplementos/no/clara-2006-06-15.html

8. http://www.pagina 12.com.ar/diario/suplementos/no/clara-2006-08-31.html

9. http://www.pagina12.com.ar/diario/suplementos/no/clara-2007-11-29.html

\section{Las putas:}

1. http://www.pagina 12.com.ar/diario/suplementos/no/clara-2003-02-13.html

2. http://www.pagina 12.com.ar/diario/suplementos/no/clara-2006-12-14.html

\section{Las esposas sexys:}

1. http://www.pagina 12.com.ar/diario/suplementos/no/clara-2003-02-06.html

2. http://www.pagina12.com.ar/diario/suplementos/no/clara-2004-02-12.html

\section{La mujer androcéntrica:}

1. http://www.pagina12.com.ar/diario/suplementos/no/clara-2005-05-12.html

\section{Cuando la puta es madre:}

1. http://www.pagina12.com.ar/diario/suplementos/no/clara-2002-11-07.html

2. http://www.pagina12.com.ar/diario/suplementos/no/clara-2002-03-07.html 
